\title{
Electron Transfer via Helical Oligopeptide to Laccase Including Chiral Schiff Base Copper Mediators
}

\author{
Kumpei Kashiwagi ${ }^{1}$, Francesco Tassinari ${ }^{2}$, Tomoyuki Haraguchi ${ }^{1}$, Koyel Banerjee-Gosh ${ }^{2}$, \\ Takashiro Akitsu ${ }^{1, *}$ and Ron Naaman ${ }^{2}$ (D) \\ 1 Department of Chemistry, Faculty of Science, Tokyo University of Science, 1-3 Kagurazaka, Shinjuku-ku, \\ Tokyo 162-8601, Japan; 1318525@ed.tus.ac.jp (K.K.); haraguchi@rs.tus.ac.jp (T.H.) \\ 2 Department of Chemical and Biological Physics, Weizmann Institute of Science, 234 Herzl Street, \\ 76100 Rehovot, Israel; francesco.tassinari@weizmann.ac.il (F.T.); \\ koyel.banerjee-ghosh@weizmann.ac.il (K.B.-G.); ron.naaman@weizmann.ac.il (R.N.) \\ * Correspondence: akitsu2@rs.tus.ac.jp; Tel.: +81-3-5228-8271
}

Received: 30 March 2020; Accepted: 6 May 2020; Published: 12 May 2020

\begin{abstract}
The oxygen reduction efficiency of a laccase-modified electrode was found to depend on the chirality of the oligopeptide linker used to bind the enzyme to the surface. At the same time, the electron transfer between the cathode electrode and the enzyme is improved by using a copper(II) complex with amino-acid derivative Schiff base ligand with/without azobenzene moiety as a mediator. The increased electrochemical current under both $\mathrm{O}_{2}$ and $\mathrm{N}_{2}$ proves that both the mediators are active towards the enzyme.
\end{abstract}

Keywords: chirality; oligopeptide; laccase; copper complex; electron transfer

\section{Introduction}

To our knowledge, the first report of enzymatic biofuel cells appeared in 1964, and intensive research has been conducted on the subject ever since [1]. An enzymatic biofuel cell uses enzymes as catalysts at the anode to oxidize fuel as an electron donor and enzymes at the cathode to reduce oxygen [2]. The whole cell can convert chemical energy into electrical energy [3]. In this way, biofuel cells may be a device providing electric power by the conversion of chemical energy [2]. This principle resembles a living body with enzymes to catalyze oxidation and reduction reactions. These catalytic functions can convert the energy of the redox reaction into bioenergy [4]. An enzymatic biofuel cell has advantages, such as low environmental burden, easy safety handling, and practical downsizing [5]. However, it also has disadvantages, such as low enzyme durability and low power conversion. Therefore, it is necessary to improve the electron transfer from the cathode electrode to the active sites of the enzyme (laccase, etc.). The goal of our study is to overcome the environmental and energetic issues by developing suitable materials for low-cost and renewable energy systems using a chemical approach.

Laccase is one of the few enzymes which can be used on the cathode side of the fuel cell to reduce oxygen to water by four-electron reduction [6-8], similarly to cytochrome c oxidase [9-11]. Laccase is classified into a family of multi copper oxidases which include at least four copper ions of three types as active centers. This multi-copper oxidase receives external electrons with Type- 1 copper and reduces oxygen with Type-2 copper and two Type-3 coppers [6,7]. Electron injection from the outside of the molecular surface to the nearest active center (Type-1) of laccase is a very important step of the enzymatic reaction and an interesting research subject towards industrial applications. It is known that a hydrophobic pocket (having a high affinity for hydrophobic groups of substrates) exists near the Type-1 site. As described above, a major problem of the enzymatic biofuel cell is to efficiently 
transfer electrons from the electrode to this active center. At present, there are two main methods for promoting a more efficient electron transfer: (1) "Direct Electron Transfer" using linker molecules or appropriately molecular orientation [12,13]; (2) "Mediated Electron Transfer" using a mediator that relays electrons between the electrode surface and the molecules of enzyme proteins [14,15].

In this study, we use a combination of these two strategies, using a mediator as well as an oligopeptide bridge to order to improve the electron transfer from cathode to laccase [16]. Laccase from Trametes versicolor was employed as the enzyme catalyst in the cathode of this biofuel cell. The present study is composed of three steps (Scheme 1). The first step describes the preparation of the mediator Cu-complexes, incorporating a dipeptide Schiff base ligand with a photochromic azobenzene moiety or without it [17]. The second step describes the assembly of the mediator complex to the laccase and the characterization of the mediator functions, as well as the catalytic activity of the laccase/mediator complex. The third step describes the preparation of a modified electrode in which chiral oligopeptide linkers are used to bind the laccase/mediator complex to the electrode, in order to pass spin-polarized electrons. The third step's objective is to elucidate if the phenomenon called as Chiral-Induced Spin Selectivity (CISS) [18,19] plays a role in the electron injection into the laccase/mediator complex.

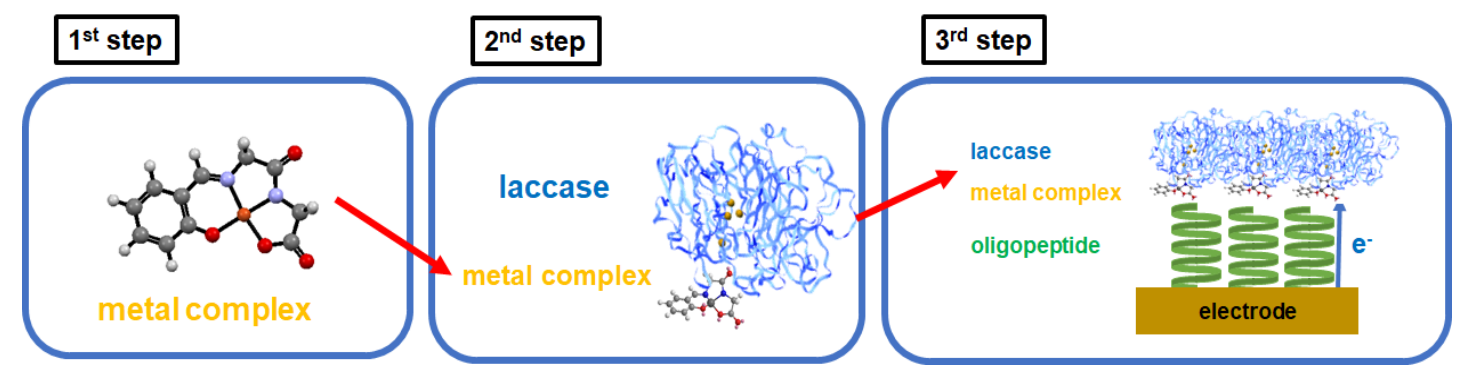

Scheme 1. Hierarchical structures of electrode materials.

\section{Materials and Methods}

\subsection{General Procedures}

Chemicals of the purest commercial grade were used as received without further purifications. All solvents were acquired from Kanto Chemical (Tokyo, Japan), reagents from Tokyo Chemical Industry (Japan), metal sources and laccase (from Trametes versicolor) from Wako (Osaka, Japan), oligopeptides $\left(L-\right.$ and $\left.D^{-}\right) \mathrm{NH}_{2}-(\mathrm{Ala}-\mathrm{Aib})_{5}-\mathrm{CONH}-\mathrm{CH}_{2}-\mathrm{CH}_{2}-\mathrm{SH}$ (where Ala = Alanine, Aib = aminoisobutyric acid) from Genemed Synthesis Inc. (USA). Complex 1 [20] and a precursor of the azo-ligand (azobenzenesalicylaldehyde) for 2 [21,22] were prepared according to literature procedures with slight modifications.

\subsection{Preparation}

\subsubsection{Preparation of $\mathbf{1}$}

Glycylglycine $(2.0 \mathrm{mmol})$ was dissolved slowly and refluxed at $313 \mathrm{~K}$ in methanol $(20 \mathrm{~mL})$ containing $\mathrm{LiOH} \cdot \mathrm{H}_{2} \mathrm{O}(2.0 \mathrm{mmol})$ for $30 \mathrm{~min}$. After cooling to $298 \mathrm{~K}$, a solution $(20 \mathrm{~mL})$ of salicylaldehyde $(2.0 \mathrm{mmol})$ as methanol solution was added slowly during stirring. After addition and stirring of this solution for $10 \mathrm{~min}, \mathrm{Cu}\left(\mathrm{NO}_{3}\right)_{2} \cdot 2.5 \mathrm{H}_{2} \mathrm{O}(2.0 \mathrm{mmol})$ was added as powder to this solution and the $\mathrm{pH}$ adjusted to be $\mathrm{pH}=10$ by the addition of a $1.0 \mathrm{M} \mathrm{NaOH}$ aqueous solution. After stirring for $30 \mathrm{~min}$ at $298 \mathrm{~K}$, the volume of the solution was reduced with a rotary evaporator to obtain crude product. Ethanol solvent was added to precipitate the product out, which was then (for purify) recrystallized using methanol. Yield: 56.73\%. Anal. Found: C; 37.07, H; 3.62, N; 7.08. Calcd. For $\mathrm{C}_{11} \mathrm{H}_{13} \mathrm{~N}_{2} \mathrm{O}_{6} \mathrm{CuNa}_{\mathrm{N}}$ C; 37.14, H; 3.68, N; 7.87\%. IR (KBr): $1634 \mathrm{~cm}^{-1}(\mathrm{C}=\mathrm{N})$. UV-vis (methanol): 240, 290, $380 \mathrm{~nm}$. 


\subsubsection{Preparation of 2}

Glycylglycine $(2.0 \mathrm{mmol})$ was dissolved completely and refluxed at $313 \mathrm{~K}$ in methanol $(20 \mathrm{~mL})$ containing $\mathrm{LiOH} \cdot \mathrm{H}_{2} \mathrm{O}(2.0 \mathrm{mmol})$ for $30 \mathrm{~min}$. After cooling to $298 \mathrm{~K}$, a solution of azobenzenesalicylaldehyde $(2.0 \mathrm{mmol})$ in methanol $(20 \mathrm{~mL})$ was added slowly (almost dropwise) under stirring. After stirring for $10 \mathrm{~min}$, then $\mathrm{Cu}\left(\mathrm{NO}_{3}\right)_{2} \cdot 2.5 \mathrm{H}_{2} \mathrm{O}(2.0 \mathrm{mmol})$ was added as powder to this solution and the $\mathrm{pH}$ adjusted to be $\mathrm{pH}=10$ by the addition of a $1.0 \mathrm{M} \mathrm{NaOH}$ solution. After stirring at the same temperature for $30 \mathrm{~min}$, the volume of the solution was reduced slowly with a rotary evaporator to obtain crude product. The solvent was dried, and the final sample was isolated by recrystallization from methanol (Scheme 2). Anal. Found: C; 43.64, H; 3.80, N; 13.03. Calcd. For $\mathrm{C}_{17} \mathrm{H}_{17} \mathrm{~N}_{4} \mathrm{O}_{6} \mathrm{CuNa}$ C; 44.40, H; 3.73, N; 13.18\%. IR (KBr): $1622 \mathrm{~cm}^{-1}(\mathrm{C}=\mathrm{N})$. UV-vis (methanol): 240, $290(\mathrm{sh}), 375 \mathrm{~nm}$.

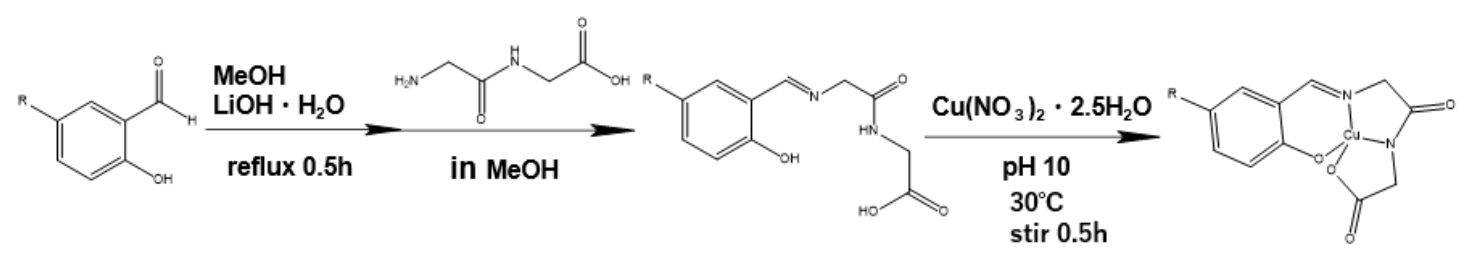

Scheme 2. Preparations of $\mathbf{1}(\mathrm{R}=\mathrm{H})$ and $\mathbf{2}\left(\mathrm{R}=\mathrm{N}=\mathrm{N}-\mathrm{C}_{6} \mathrm{H}_{5}\right)$.

\subsubsection{Electrode Fabrication}

In order to elucidate the electron transfer process within the enzyme, we adsorbed the laccase onto a Self-Assembled Monolayer (SAM) coated on a gold electrode. For the formation of the monolayer, oligopeptides having the structure Cya-(Ala-Aib) $5-\mathrm{NH}_{2}$ (Cya = Cysteamine) were used. Two different types of this oligopeptide were used separately in the experiments, one having L-Ala amino acids in the sequence, the other having $D$-Ala amino acids. The $L$-oligopeptide with terminal groups forms a right-handed, $\alpha$-helix structure in the SAM, while the $D$-form, with terminal groups, a left-handed helix.

The procedure for preparing the electrode is described below. Before preparation, the electrodes were then washed with ethanol, acetone and water and then used for the experiments. The gold surfaces were carefully washed by boiling them in acetone solvent without further treatment and then in ethanol for 10 min each time, and then immersing them in ethanol solvent for $40 \mathrm{~min}$ without plasma cleaning. Thereafter, $1 \mathrm{mg}$ of the oligopeptide was completely dissolved in $1.6 \mathrm{~mL}$ of a mixed solution of 2,2,2-trifluoroethanol (TFE) $/ \mathrm{H}_{2} \mathrm{O}=2 / 3 \mathrm{v} / \mathrm{v}$, and the cleaned electrode was incubated in this solution for $48 \mathrm{~h}$. The electrode was removed from the oligopeptide solution, rinsed with ethanol, acetone, and isopropanol and then dried with $\mathrm{N}_{2}$. Then, the electrode was placed in a solution in which $20 \mathrm{mg}$ of laccase and $10 \mathrm{mg}$ of the complex were carefully dissolved in $4 \mathrm{~mL}$ of phosphate buffer ( $\mathrm{pH} 7.3$ ), and incubated for $48 \mathrm{~h}$.

\subsubsection{ABTS Assay Procedures}

2,2' -azino-bis(3-ethylbenzothiazoline-6-sulfonic acid (ABTS) is often used as an oxidation substrate to assess the catalytic activity of the laccase. The absorbance of the UV-vis spectral peak at about $417 \mathrm{~nm}$ was attributed to the oxidized ABTS and can indicate the activity of enzyme as the biocatalyst.

\subsection{Physical or Instrumental Measurements}

Elemental analyses (C, H and N) were measured using a Perkin-Elmer (Waltham, USA) 2400 II CHNS/O analyzer. Infrared (IR) spectra were measured on a JASCO (Tokyo, Japan) FT-IR 4200 spectrophotometer in the range of $400-4000 \mathrm{~cm}^{-1}$ at $298 \mathrm{~K}$. UV-vis (electronic) spectra were measured on a JASCO (Tokyo, Japan) V-650 spectrophotometer in the range of 800-220 nm at $298 \mathrm{~K}$. Circular dichroism (CD) spectra were measured on a JASCO (Tokyo, Japan) J-725 spectropolarimeter in the range of $200-800 \mathrm{~nm}$ at $298 \mathrm{~K}$. Electrochemical, namely cyclic voltammetry (CV), measurements 
were carried out on a BAS (Tokyo, Japan) SEC2000-UV/VIS and ALS2323 system in the range of $+0.80-0.50 \mathrm{~V}$ vs. $\mathrm{Ag} / \mathrm{AgCl}$ reference electrode. Light irradiation was carried out using a lamp (1.0 $\mathrm{mW} / \mathrm{cm}^{2}$ ) by Hayashi Tokei (Tokyo, Japan) with head cut filters and optical filters (UV $\lambda=200-400 \mathrm{~nm}$ ), leading to a sample by using optical fibers and polarizer through flexible optical filters by Sigma Koki (Tokyo, Japan). Spectroscopic ellipsometry was measured with a J. A. Woollam Japan (Tokyo, Japan) M-2000V-SUT ellipsometer.

\section{4. $x$-ray Crystal Structure Analysis}

Green prismatic crystals of 2 were set on top of a glass capillary, coated with a thin layer of Araldite epoxy resin. Intensity data were collected on a Bruker APEX2 CCD diffractometer (Bruker, Billerica, MA, USA) with Mo-K $\alpha$ radiation monochromated by graphite $(\lambda=0.71073 \AA)$. Data treatment used a program package "SAINT" (Bruker, Billerica, MA, USA). An empirical absorption correction for intensity was applied by the program SADABS (Bruker, Billerica, MA, USA). In this program package, the structures (phase problem) were initially solved by direct methods with a SHELXS-97 [23], expanded by Fourier techniques, and finally refined by full-matrix least-squares methods based on $F^{2}$ using a SHELXL-97 program [23]. All non-hydrogen (heavy) atoms were readily located to construct a model and refined by anisotropic (thermal) displacement parameters. All hydrogen atoms were not located at observed positions but at geometrically calculated positions and they were refined using riding models on the parent atoms. Low electron density due to solvent molecules could not be completely assigned as reasonable disorder or smoothing. Unfortunately, a suitable single crystal of $\mathbf{1}$ could not be obtained.

Crystallographic data for 2: $\mathrm{C}_{17} \mathrm{H}_{13} \mathrm{CuN}_{4} \mathrm{O}_{4} \cdot \mathrm{H}_{2} \mathrm{O}$, Triclinic, space group $P-1$ (\#2), $\mathrm{Z}=2, a=6.4450$ (3) $\AA, b=8.5210(4) \AA, c=16.3926(8) \AA, \alpha=77.986(2), \beta=89.626(2)^{\circ}, \gamma=80.815(2)^{\circ}, V=868.91(7) \AA^{3}$, $\rho_{\text {calc }}=1.548 \mathrm{gcm}^{-3}, \mu=1.28 \mathrm{~mm}^{-1}, F(000)=416, S=1.116, R_{1}[I>2 \sigma(I)]=0.0699, w R 2=0.1861$. $T=173 \mathrm{~K}$.

\subsection{Computational Calculations}

The calculations of the optimized structure of $\mathbf{1}$ and $\mathbf{2}$ were carried out using the Gaussian 09W software package Revision D.02 (Gaussian, Inc., Wallingford, CT, USA) [24] with a Windows 10 personal computer. All geometries have been optimized by using B3LYP level of theory and basis set SDD. The frequency calculations were performed for the optimization of geometries using the identical level of theory and basis set.

The complexes $\mathbf{1}$ and $\mathbf{2}$ and laccase docking simulations were performed using a GOLD suite (ver. 5.5.0) [25]. We used structural data 1GYC of Laccase from Trametes versicolor from the Protein Data Bank [26] and used them to calculate how 1 and 2 behave in the vicinity of a so-called hydrophobic pocket at the surface outside of Type-1 site.

\section{Results and Discussion}

\subsection{Copper Complexes}

The dipeptide derivative of $\mathbf{2}$ affords a four-coordinated square planar coordination environment (Figure 1). There are no planar geometries in similar types of dipeptide Schiff base ligands [27,28], or azobenzene [29] moieties. In contrast to crystal structure, the optimized structure of 2 affords a distorted tetrahedral coordination environment (Figure 2). 


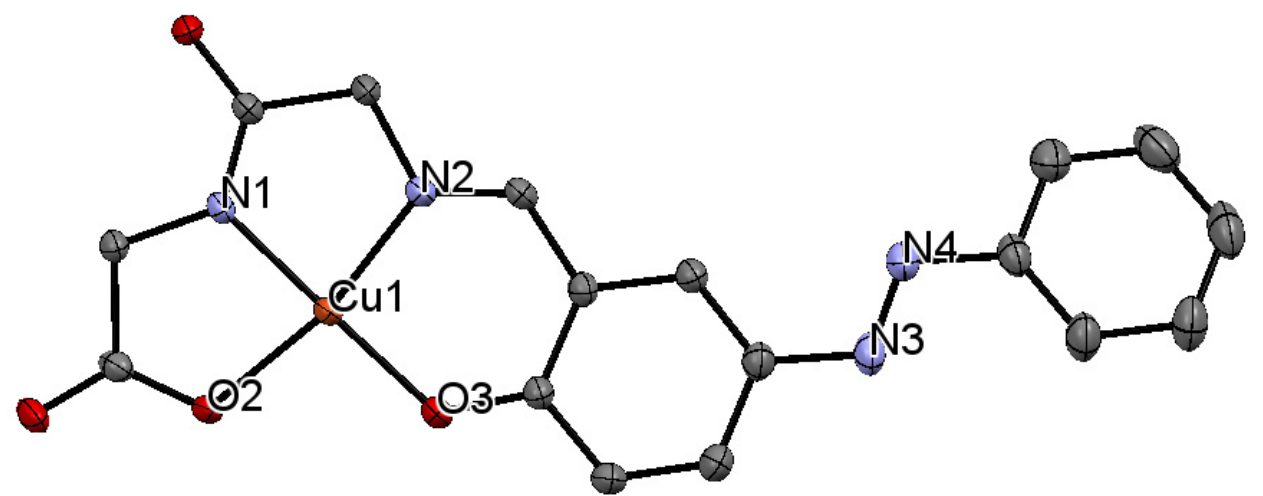

Figure 1. Crystal structures of 2. Hydrogen atoms and water molecule were omitted for clarity. Selected bond distances $[\AA]$ and angles $\left[{ }^{\circ}\right]:$ Cu1-N1 $=1.894(4), \mathrm{Cu}-\mathrm{O} 3=1.899(3)$, Cu1-N2 = 1.927(4), Cu1-O2 = 1.978(3), N3-N4 = 1.260(6), N1-Cu1-O3 = 176.80(16), N1-Cu1-N2 = 84.07(15), O3-Cu1-N2 = 94.78(14), N1-Cu1-O2 = 83.06(14), O3-Cu1-O2 = 97.91(13), N2-Cu1-O2 = 166.77(14).

1

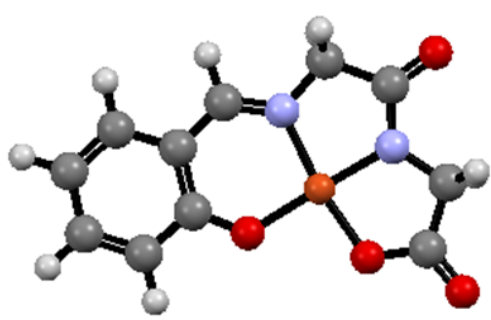

2

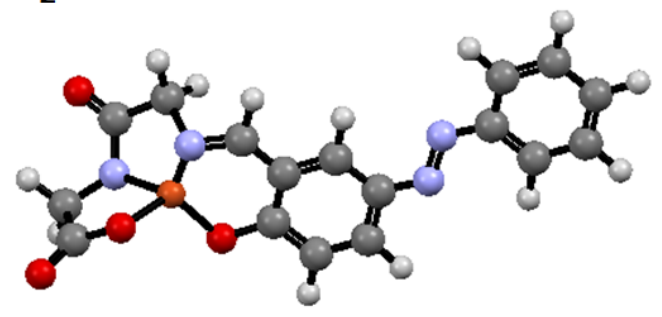

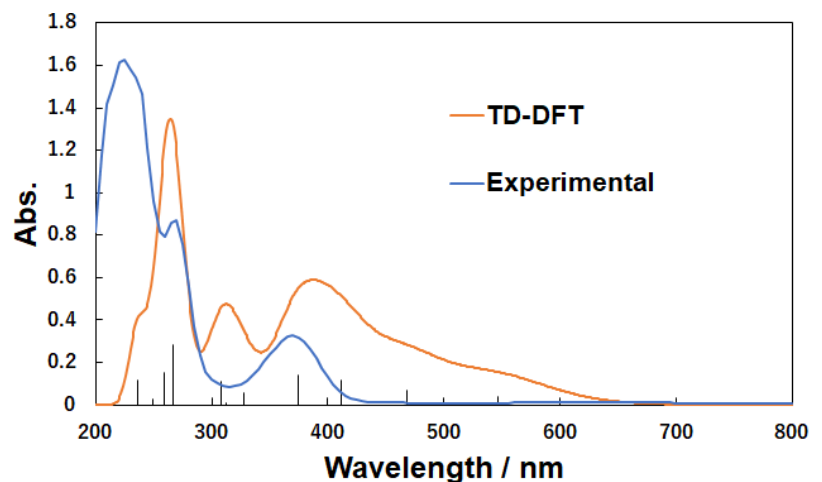

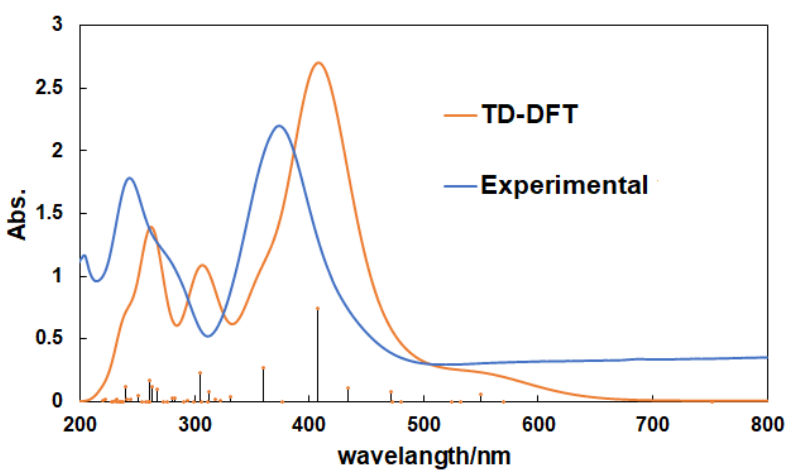

Figure 2. Optimized structures and experimental and calculated electronic spectra of $\mathbf{1}$ and $\mathbf{2}$.

The UV-vis spectrum of $\mathbf{1}$ (taken as a methanol solution) exhibits intense $\pi-\pi^{*}$ bands at around 200 to $300 \mathrm{~nm}$ due to the Schiff base ligand moiety (and a quite weak $\mathrm{d}-\mathrm{d}$ band), whose assignment was also confirmed by simulated spectra from DFT calculations giving theoretical values of 267.17, 308.03, 374.29, and $411.39 \mathrm{~nm}$ (Figure 2). The UV-vis spectrum of 2 in methanol solution exhibits intense $\pi$ - $\pi^{*}$ bands as well as an $n-\pi^{*}$ transition of azo-group around $375 \mathrm{~nm}$ (Figure 3 ). After alternative irradiation of UV light and visible light, trans-photoisomerization/cis-photoisomerization of 2 could be observed reversibly for at least four cycles [30]. 

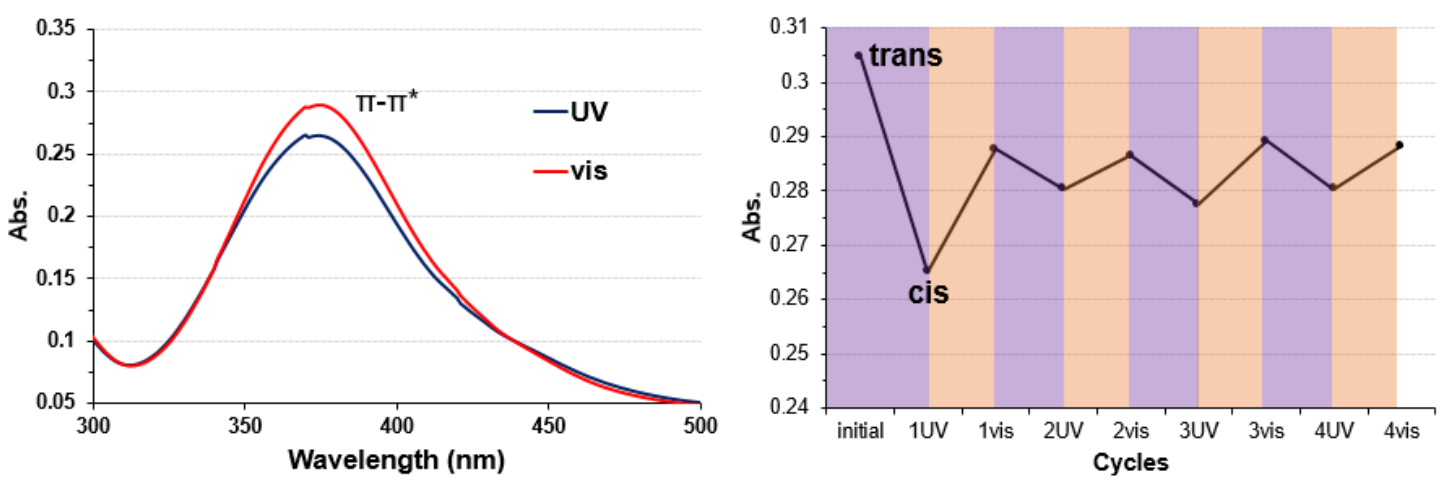

Figure 3. (Left) UV-vis spectra of 2 with azo-group. (Right) Cycle index of trans/cis-photoisomerization of 2.

The results of cyclic voltammetry (CV) of $\mathbf{1}$ and $\mathbf{2}$ are shown in Figure 4. The anaerobic measurement was carried out using a carbon paste electrode as the working electrode (excluded the effect of carbon paste electrode). The buffer used was a $10 \mathrm{mM}$ phosphate buffer at $\mathrm{pH}=7.3$, and the scan rate of $\mathrm{CV}$ was $50 \mathrm{mV} / \mathrm{s}$. In both complexes, a redox peak derived from the central $\mathrm{Cu}(\mathrm{II} / \mathrm{I})$ ion $\left(E^{0}=+0.157 \mathrm{~V}\right)$ was observed. For 1 a second, smaller redox peak due to the ligand $\left(E^{0}=-0.322 \mathrm{~V}\right)$ was also observed [28]. As for 2, a second peak deriving from the redox activity of the azo-moiety $\left(E^{0}=-0.309 \mathrm{~V}\right)$ was seen to depend on whether the solution was irradiated with UV or visible light. Thus, the current density for 2 was increased by cis-trans isomerization by light irradiation [31,32]. However, in contrast to UV-vis spectra, the CV pattern of $\mathbf{2}$ was not reversible after cis-trans isomerization, because of unexpected changes in azo-moiety such as protonation. Thus, the red curve did not go back on the blue one by visible light in this case.
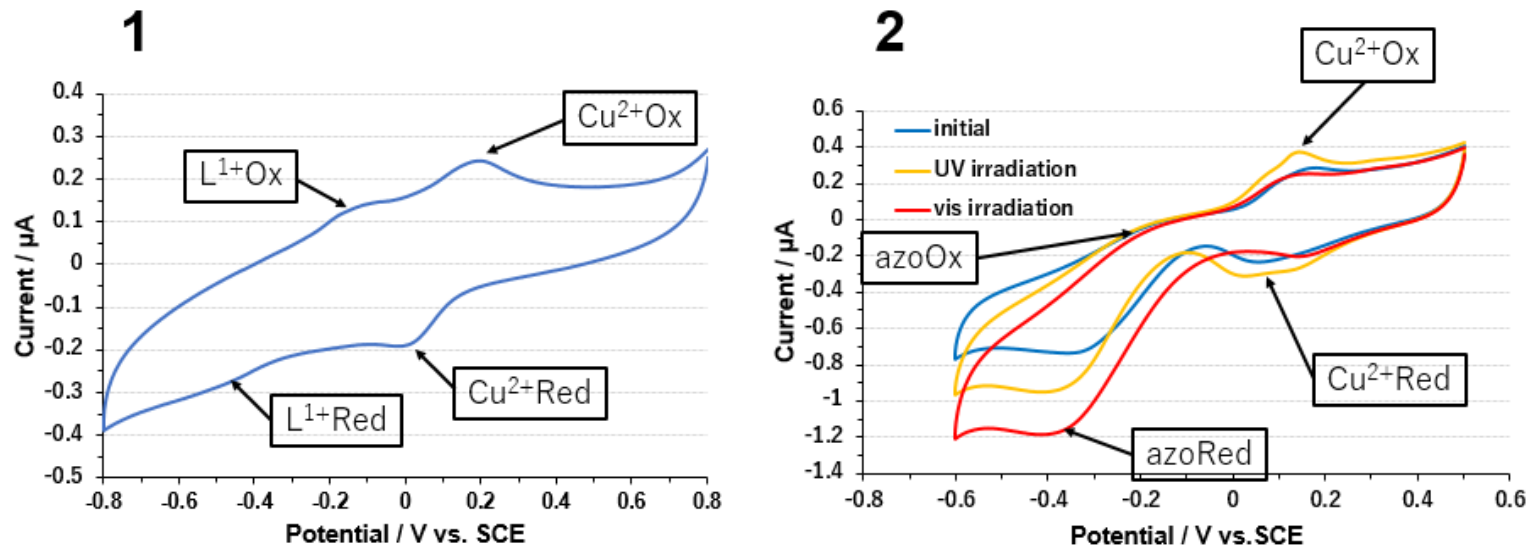

Figure 4. (Left) CV for 1. (Right) CV for 2 before light irradiation (blue; trans-form) and after UV light irradiation (orange; cis-form) and visible light irradiation (red; trans-form) for $3 \mathrm{~min}$.

\subsection{Copper Complexes and Laccase}

$\mathrm{CD}$ measurements of pure laccase $(16 \mu \mathrm{M})$ and of a mixture of laccase and $\mathrm{Cu}$-complexes 1 or 2 in a 1:1 ratio $(16 \mu \mathrm{M})$ were carried out in $10 \mathrm{mM}$ phosphate buffer solution of $\mathrm{pH} 7.3$ (Figure 5). Compared to laccase, laccase with complexes showed a decreased intensity of the negative peaks at $216 \mathrm{~nm}$ (attributed to $\beta$-sheet) and $230 \mathrm{~nm}$ (attributed to random coil). This behavior seems to hint at a loss of both $\beta$-sheet and $\beta$-turn content in the laccase structure, suggesting that complexing the laccase with the $\mathrm{Cu}$ (II) complexes may result in slightly structural changes in the enzyme, allowing easier access to the Type-1 copper active site. 

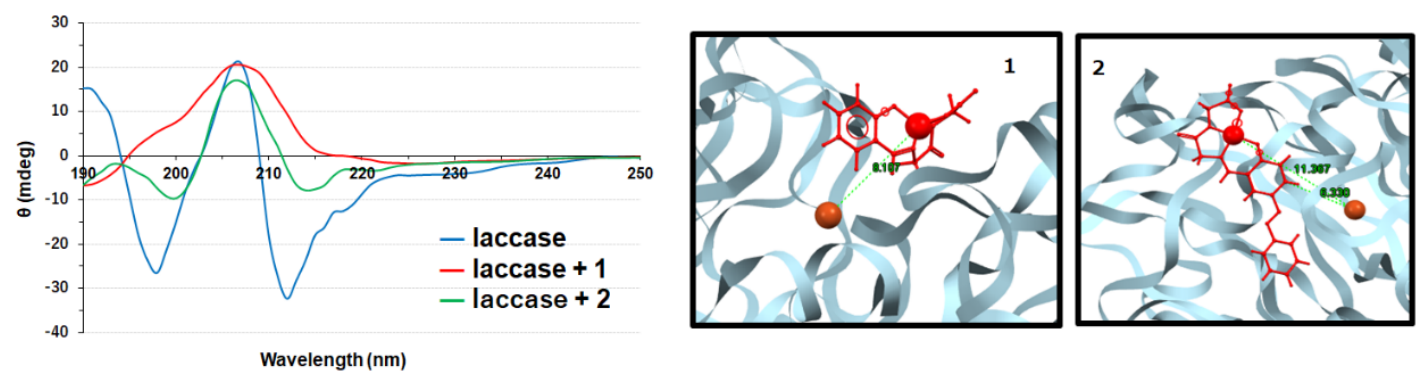

Figure 5. (Left) circular dichroism (CD) spectra for laccase (blue), laccase+1 (red), and laccase+2 (green). (Right) Docking simulation with GOLD for laccase+1 and laccase+2 to estimate distance between $\mathrm{Cu}(\mathrm{II})$ ion of complexes and Type-1 copper site (electron acceptor) of laccase.

Docking simulation suggested thermodynamically stable docking conformation of the complexes onto the surface of laccase, especially around the hydrophobic pocket near the Type-1 copper site [33-35]. The lowest energy docking poses for both complexes are very close to the laccase, with interatomic distance of the two $\mathrm{Cu}$ atoms of $8.107 \AA$ (docking score $=41.4037$ ) for 1 and $6.330 \AA$ (docking score $=46.1320$ ) for $\mathbf{2}$. The better docking score of $\mathbf{2}$ may be due to hydrophobic interactions between the pocket and the azobenzene moiety (Figure 5) [22,31,32].

An ABTS essay measurement was performed to confirm the activity of the laccase/mediator complex (Figure 6) [36]. $0.1 \mathrm{~mL}$ laccase, laccase $+\mathbf{1}$ or laccase +2 solutions $(0.5 \mathrm{mg} / \mathrm{mL})$ was mixed with a $2.9 \mathrm{~mL}$ ABTS solution $(0.5 \mathrm{mM})$ fast, and the enzyme activity was examined by following the UV-vis peak at $420 \mathrm{~nm}$ (peak of the oxidized ABTS) over time. However, reliable standard values of laccase's activity were not clear in this case. The resulting slopes (Abs/Time) were $3.23 \times 10^{-4}, 4.89 \times 10^{-4}$, and $2.05 \times 10^{-4} \mathrm{~min}^{-1}$ for laccase, laccase $+\mathbf{1}$ or laccase +2 , respectively. The laccase enzymatic activity after complexation with the two different mediators stayed in the same order of magnitude qualitatively. Unfortunately, quantitatively reliable values of activity could not be obtained because of the addition of mediators and treatment of background throughout this study.

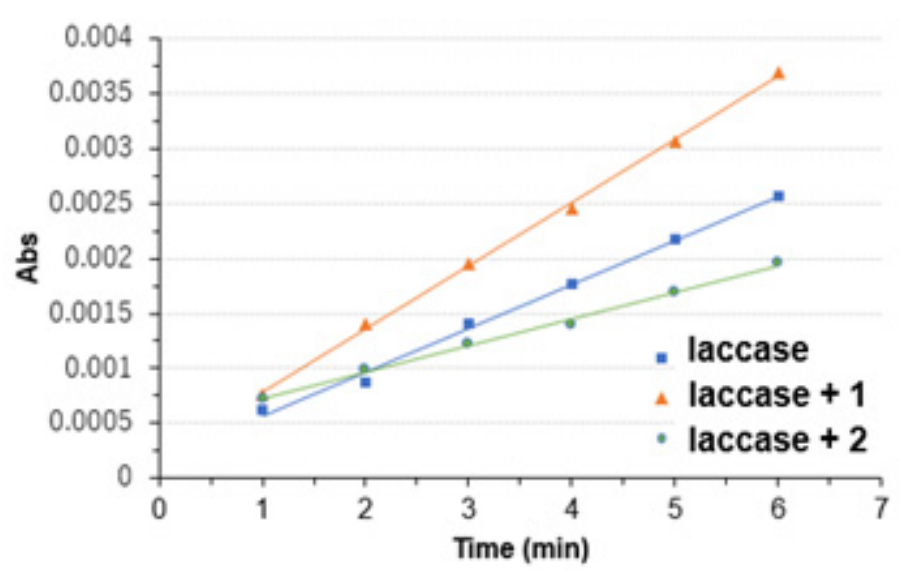

Figure 6. ABTS assay for laccase (blue), laccase+1 (red), and laccase+2 (green).

The CV of laccase $+\mathbf{1}$ and laccase $+\mathbf{2}$ are shown in Figure 7. The redox peak of the Type- 1 copper due to the four-electron reduction of oxygen to water by laccase and a reduction peak can be seen under oxygen filling. A modified glassy carbon (GC) electrode was employed as the working electrode. First, $5 \mathrm{mg}$ of the complex was carefully dissolved in $0.5 \mathrm{~mL}$ of ultrapure water and sonicated, and $40 \mu \mathrm{L}$ of the obtained solution was drop-casted on the GC electrode. After this, $10 \mu \mathrm{L}$ of a $20 \% \mathrm{w} / \mathrm{w}$ methanol solution of glutaraldehyde was added dropwise. In the end, a laccase solution ( $5 \mathrm{mg}$ of laccase, $20 \mu \mathrm{L}$ of Nafion ${ }^{\circledR}$ in $0.5 \mathrm{~mL}$ of ultrapure water) was added dropwise. All the subsequent drop-casting was performed without letting the surface to dry completely. At this point, the surface was allowed to dry 
completely and a Nafion ${ }^{\circledR}$ membrane was formed. In order to confirm the four-electron reduction of oxygen by laccase, monitoring with an $\mathrm{O}_{2}$ meter, measurements under saturated (saturation is known to be $7.97 \mathrm{mg} / \mathrm{L}$ for pure water at $300 \mathrm{~K}$ under $1 \mathrm{~Pa}$ air) oxygen filling (added $\mathrm{O}_{2} 20 \mathrm{mg} / \mathrm{L}$ or more, which was monitored by decreasing of gas and resulting in oxygen monitor's constant saturation) and under nitrogen filling were performed and compared [32,34,35]. Possible data corresponding to the blank tests may be found in Figure 4 and Figure S1), in this case. Blank experiments for laccase only systems were also added as Figures S2 and S3. No experimental proof of releasing free $\mathrm{Cu}(\mathrm{II})$ ion from chelate ligand could be observed in Figure 4 at least.
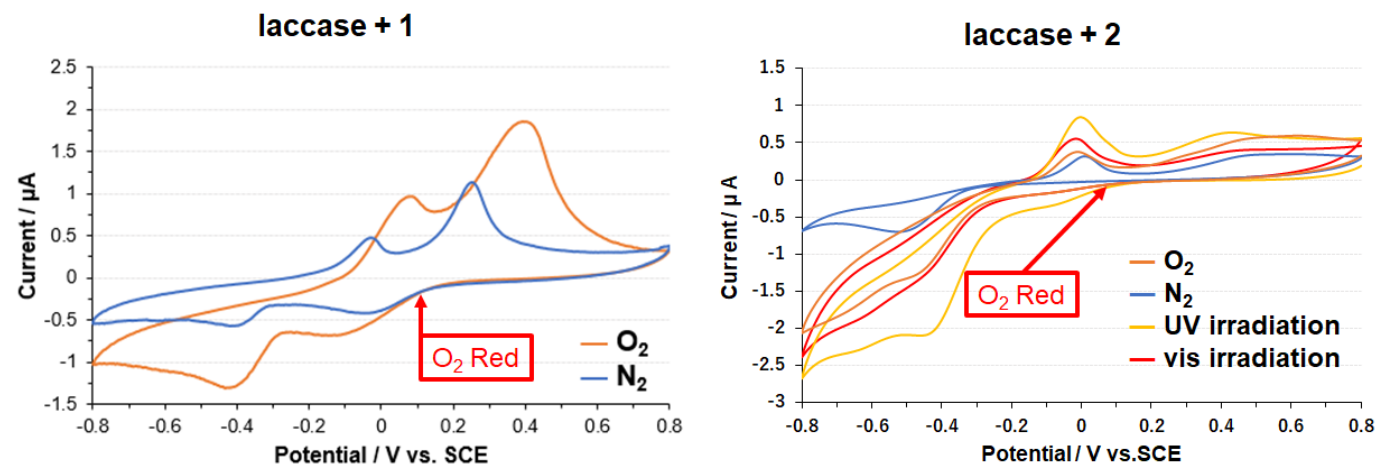

Figure 7. (Left) CV for laccase under nitrogen (blue) and oxygen (orange). (Right) CV for laccase+2 under nitrogen or oxygen atmosphere, and under oxygen before light irradiation (trans-form) and after UV light irradiation (cis-form) and visible light irradiation (trans-form) for $3 \mathrm{~min}$.

It was found that under oxygen filling the onset of the reduction peaks of the Type- 1 copper, where usually value was observed for the pure laccase (shown in Figure S1), were shifted to more positive potentials for both the laccase/mediator complexes. This onset of shifts increases the total current density and shows the usefulness of the mediator. The redox peak due to the $\mathrm{Cu}$-complex was also observed. For the laccase +2 complex, light-dependent measurements were performed after irradiating the surface with ultraviolet light and visible light. The redox current increased upon irradiation with ultraviolet light. Electron transfer seems to be more efficient after the laccase/complex is irradiated with UV light, that is, when the azo-group is in the cis-form [31,32,37]. For both complexes, the current density was increased in the presence of oxygen. Both complexes of $\mathbf{1}$ and $\mathbf{2}$ were confirmed to be useful as mediators.

\subsection{Electrode on Gold Substrate Composed of Oligopeptide, Copper Complexes, and Laccase}

Two different oligopeptides were used for linking the laccase/mediator complex to a gold electrode. Their general structure was $\mathrm{NH}_{2}-(\mathrm{Ala}-\mathrm{Aib})_{5}-\mathrm{CONH}-\mathrm{CH}_{2}-\mathrm{CH}_{2}-\mathrm{SH}$, where Aib is aminoisobutyric acid, and Ala is either L-alanine or D-alanine. The presence of the thiol group allows for the formation of a SAM on the electrode gold surface. These oligopeptides form $\alpha$-helixes of opposite chirality on the surface, depending on which alanine enantiomer is present in their molecular structure (Scheme 3). Previous studies by Kiran, Cohen and Naaman have shown that these oligopeptides can give spin selectivity [38]. The amine group present on the terminal end is used to adsorb the laccase/mediator complex, exploiting the carboxylic residues on the laccase surface. ABTS essay measurements were performed to confirm the activity of the laccase including a mediator complex bound to the surface through the oligopeptide monolayer. As mentioned in 3.2 (mentioned in the slope values), the resulting slopes (Abs/Time) were $3.44 \times 10^{-4}, 2.79 \times 10^{-4} .4 .86 \times 10^{-4}$ and 3.31 $\times 10^{-4} \mathrm{~min}^{-1}$ for $L$-oligopeptide+laccase $+\mathbf{1}, L$-oligopeptide+laccase $+2, D$-oligopeptide+laccase $+\mathbf{1}$, $D$-oligopeptide+laccase +2 , respectively. Thickness of the inclined monolayers of $L$ - and $D$-oligopeptides $(1.71 \pm 0.067 \mathrm{~nm}$ and $1.80 \pm 0.066 \mathrm{~nm})$ and $L-$ and $D$-oligopeptides+laccase $(4.93 \pm 0.068 \mathrm{~nm}$ and $5.11 \pm$ 
$0.068 \mathrm{~nm}$ ) was measured using ellipsometry (Figure 8). The catalytic activity of laccase was preserved even after adsorption of the $\mathrm{Cu}$ (II) complexes on the oligopeptide-bridging electrodes.

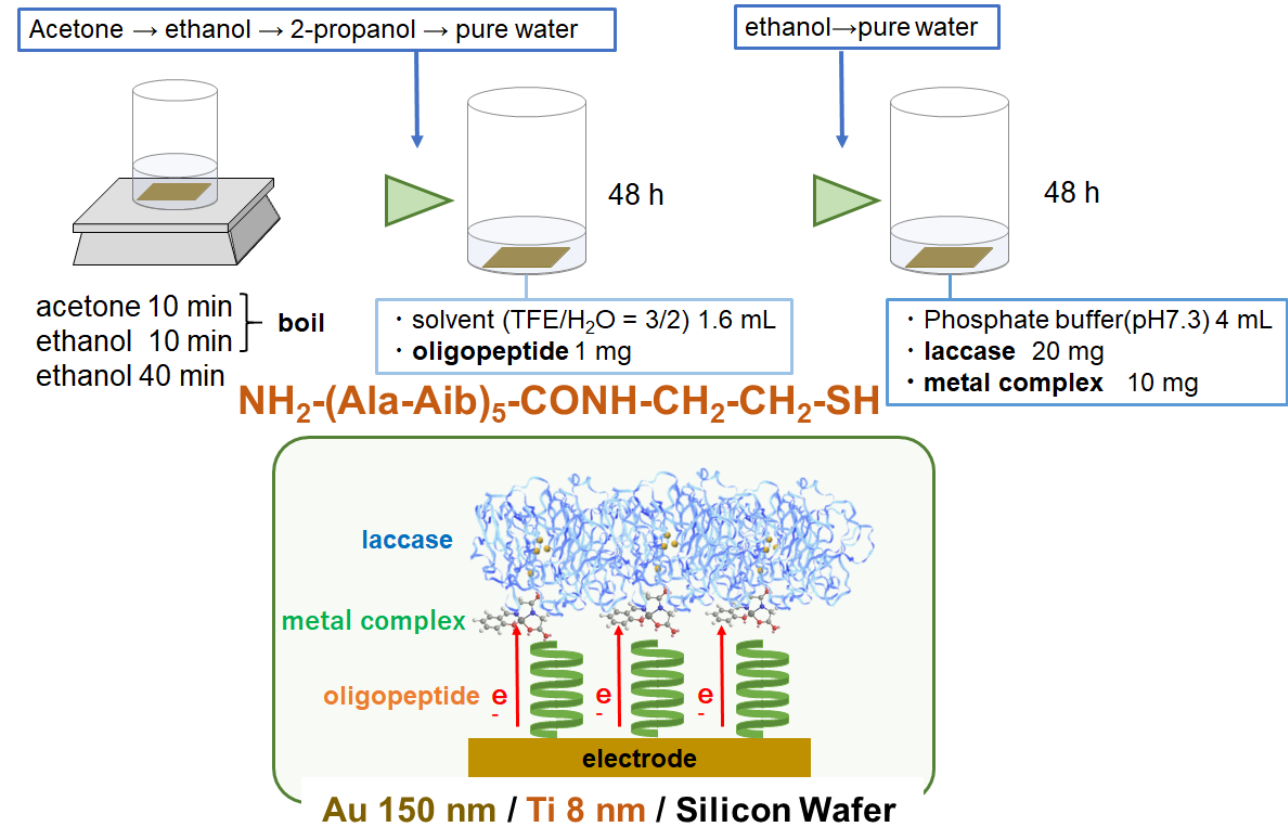

Scheme 3. Preparation and structures of electrode materials.

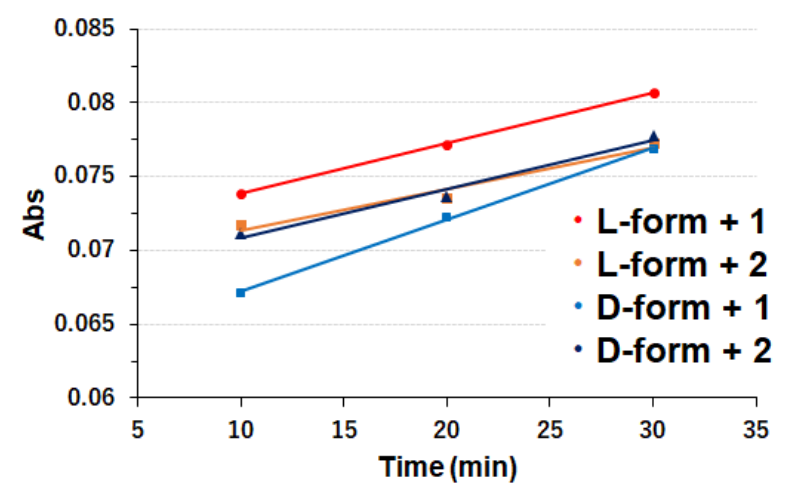

Figure 8. ABTS assay for L-oligopeptide+laccase+ 1 (red), L-oligopeptide+laccase+ 2 (orange), D-oligopeptide+laccase+ 1 (blue), D-oligopeptide+laccase+2 (violet).

The results of cyclic voltammetry using the SAM-modified electrodes are shown in Figures 9 and 10. The redox peak around $0.21 \mathrm{~V}$ observed for both the $L$-form and $D$-form can be inferred to be due to the laccase Type- 1 copper. The redox peak was significantly reduced upon consecutive cycling only in the case of $D$-form without magnetic field in this case. For complex $\mathbf{2}$, the redox peak at around $0.23 \mathrm{~V}$ observed for both the $L$-form and the $D$-form can be presumed to be due to laccase Type- 1 copper. The reduction in the redox peak was remarkably observed only in the $D$-form, as in the case of complex 1. The difference in the current of CV could be observed, and the difference between the two samples compared for each case was only the chirality of polypeptides as bridges for electron conduction. 

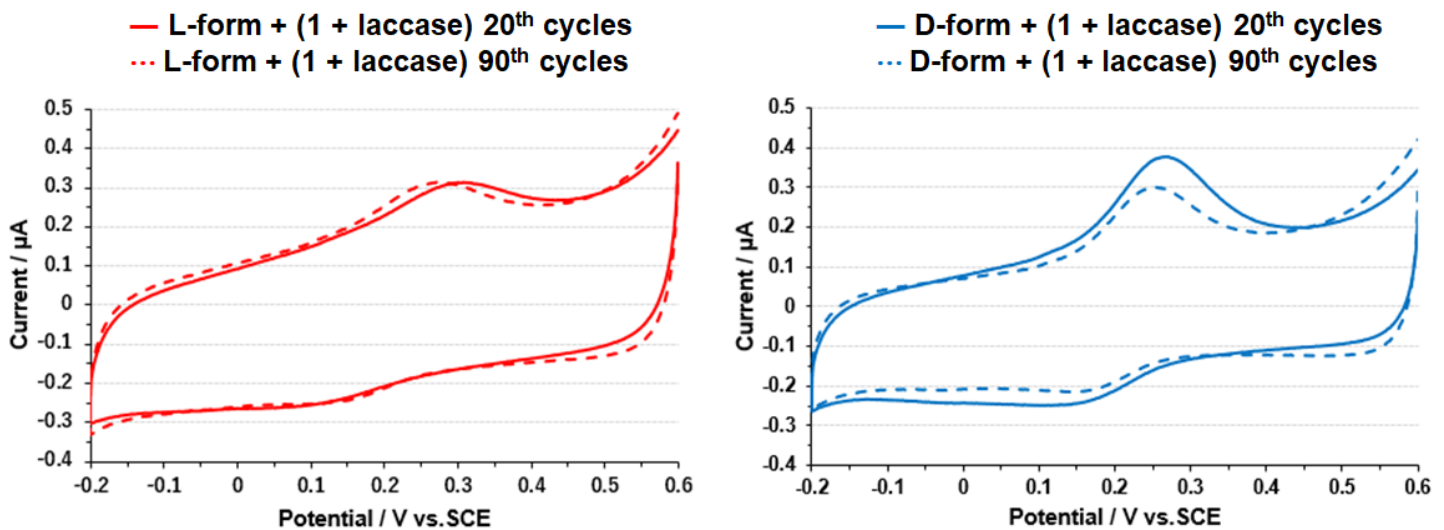

Figure 9. (Left) CV for L-oligopeptide+laccase+1 after 20 (solid line) or 90 (dashed line) electrochemical cycles. (Right) CV for D-oligopeptide+laccase+1 after 20 (solid line) or 90 (dashed line) electrochemical cycles.
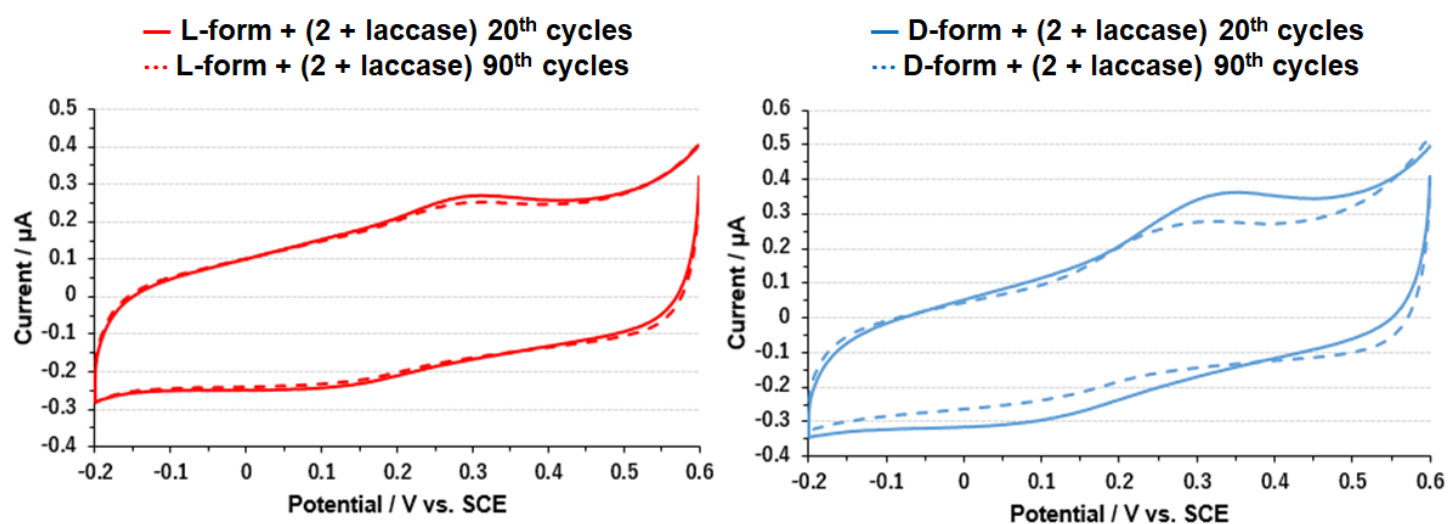

Figure 10. (Left) CV for $L$-oligopeptide+laccase+2 after 20 (solid line) or 90 (dashed line) cycles of reactions. (Right) CV for D-oligopeptide+laccase+2 after 20 (solid line) or 90 (dashed line) cycles of reactions.

For 2, CV measurements were performed after light irradiation (Figure 11). Interestingly, it was observed that the performance of the mediator, seen in the increase in current density upon irradiation with ultraviolet light, was exhibited only through the $D$-form oligopeptide.
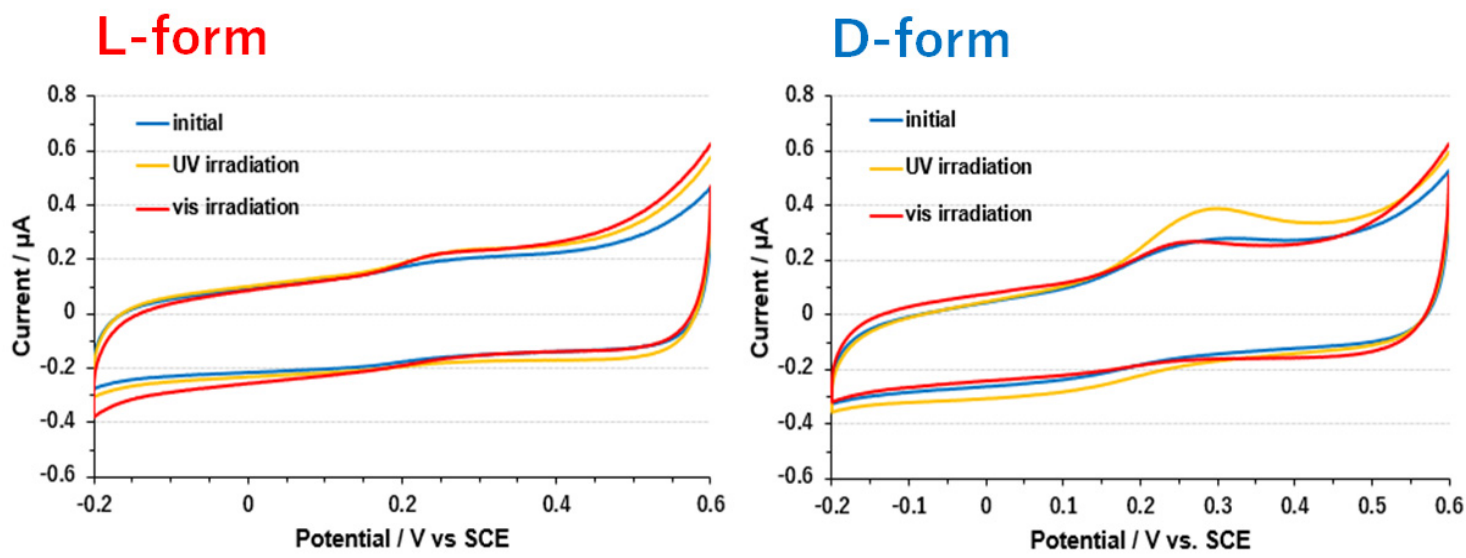

Figure 11. (Left) CV for $L$-oligopeptide+laccase+2 before light irradiation (blue, trans-form) and after UV light irradiation (orange, cis-form) and visible light irradiation (red, trans-form) for $3 \mathrm{~min}$. (Right) CV for D-oligopeptide+laccase+2 before light irradiation (blue, trans-form) and after UV light irradiation (orange, cis-form) and visible light irradiation (red, trans-form) for $3 \mathrm{~min}$. 
Theoretical models of electron conduction through helical molecules were proposed, considering the interaction between molecular orbitals and spins [39-43]. According to these studies, the dipole moment of helical molecules and a spin-orbit term coming from the chiral potential are important for the emergence of the CISS effect. The electron spin can thus have a large effect upon the electron transport, which can also be enhanced by spin-orbit interaction and accompanying tunnel effect. However, electron conductivity observed experimentally through short helical organic molecules is much larger than what expected based on theoretical calculations. In this way, while there have been only few experimental examples, the electron transfer mechanism depending on spin polarization should be considered in the presence of chiral small molecules.

To date, CISS effect has been confirmed for oligopeptides [19,38], double-stranded DNA [44], and other biomolecules [45]. Among them, especially, it should be noted that in cytochrome c (whose functions are electron donor to an oxygen-reducing enzyme cytochrome c oxidase [46]), spin-polarized electron transport was reported, suggesting the possible application of the CISS effect in improving the electron transfer in biochemical reactions, focusing on spatial properties of the enzymes, such as orientation of dipoles [47].

In recent years, we have studied the employment of spatial interactions between various metal complexes as mediators and laccase to improve the oxygen reduction ability, mainly focusing on the effect of substituent groups of the complexes prepared. On the other hand, for enhancing the efficiency of electron transfer to the enzyme using different approaches, the CISS effect could also be valid. In this work we have succeeded in proposing a new concept of hybrid system of "direct and mediated" electron transfer to laccase [48] in which transmission of spin-polarized electrons could be controlled by chirality of the oligopeptide as spin filter.

\section{Conclusions}

In summary, two dipeptide-based Schiff base $\mathrm{Cu}(\mathrm{II})$ complexes (1 and $\mathbf{2})$ were compared as a mediator between an electrode and laccase. One of them incorporates azobenzene moiety exhibiting cis-trans photoisomerism accompanied by changing electrochemical properties. ABTS assay indicated that laccase did not lose the activity of enzymatic reactions when the complexes are included into laccase molecules. The surface of gold substrate and laccase, including the complexes, were linked with enantiomers of oligopeptide acting as a path of electron transfer. In these hybrid electrode materials, laccase indicated enzymatic activity and the complexes acted as a mediator, which can be tuned by molecules ( $\mathbf{1}$ or $\mathbf{2}$ ) as well as cis-trans photoisomerization for $\mathbf{2}$. For the first time, the CV behavior indicated that difference in electron transfer to laccase with the mediator via oligopeptide could be observed due to chirality of oligopeptide, which can be regarded as a spin filter without an external magnetic field.

Supplementary Materials: The following are available online at http://www.mdpi.com/2073-8994/12/5/808/s1, Figure S1: CV for only laccase, Figure S2: CV of a bare GC electrode.

Author Contributions: Experiments, K.K., F.T., K.B.-G.; Writing Paper, T.H., T.A. Supervision, R.N. All authors have read and agreed to the published version of the manuscript.

Funding: This research received no external funding.

Acknowledgments: The author thanks Hiroki Tanaka at Waseda Nanotechnology Research Institute for teaching about electrode fabrication. F.T., K.B.-G., and R.N. acknowledge the support of the Israel Science Foundation, The MINERVA foundation and the John Templeton Foundation.

Conflicts of Interest: The authors declare no conflict of interest.

\section{References}

1. Mano, N.; de Poulpiquet, A. $\mathrm{O}_{2}$ Reduction in Enzymatic Biofuel Cells. Chem. Rev. 2018, 118, 2392-2468. [CrossRef] [PubMed] 
2. Goff, A.; Holzinger, M.; Cosnier, S. Recent progress in oxygen-reducing laccase biocathodes for enzymatic biofuel cells. Cell. Mol. Life Sci. 2015, 72, 941-952. [CrossRef] [PubMed]

3. Moehlenbrock, M.J.; Minteer, S.D. Extended lifetime biofuel cells. Chem. Soc. Rev. 2008, 37, 1188-1196. [CrossRef] [PubMed]

4. Xiao, X.; Xia, H.-Q.; Wu, R.; Bai, L.; Yan, L.; Magner, E.; Cosnier, S.; Lojou, E.; Zhu, Z.; Liu, A. Tackling the Challenges of Enzymatic (Bio)Fuel Cells. Chem. Rev. 2019, 119, 9509-9558. [CrossRef] [PubMed]

5. Sakai, H.; Mita, H.; Sugiyama, T.; Tokita, Y.; Shirai, S.; Kano, K. Construction of a Multi-stacked Sheet-type Enzymatic Biofuel Cell. Electrochemistry 2014, 82, 156-161. [CrossRef]

6. Solomon, E.I.; Szilagyi, R.K.; DeBeer George, S.; Basumallick, L. Electronic structures of metal sites in proteins and models: Contributions to function in blue copper proteins. Chem. Rev. 2004, 104, 419-458. [CrossRef]

7. Quintanar, L.; Stoj, C.; Taylor, A.B.; Hart, P.J.; Kosman, D.J.; Solomon, E.I. Shall we dance? how a multicopper oxidase chooses its electron transfer partner. Chem. Rev. 2007, 40, 445-452.

8. Mehra, R.; Muschiol, J.; Meyer, A.S.; Kepp, K.P. A structural-chemical explanation of fungal laccase activity. Sci. Rep. 2018, 8, 17285. [CrossRef]

9. Yoshikawa, S.; Shimada, A. Reaction Mechanism of Cytochrome c Oxidase. Chem. Rev. 2015, 115, 1936-1989. [CrossRef]

10. Tsukihara, T.; Shimokata, K.; Katayama, Y.; Shimada, H.; Muramoto, K.; Aoyama, H.; Mochizuki, M.; Shinzawa-Itoh, K.; Yamashita, E.; Yao, M.; et al. The low-spin heme of cytochrome c oxidase as the driving element of the proton-pumping process. Proc. Natl. Acad. Sci. USA 2003, 100, 15304-15309. [CrossRef]

11. Kruse, F.; Nguyen, A.D.; Dragelj, J.; Schlesinger, R.; Heberle, J.; Mroginski, M.A.; Weidinger, I.M. Characterization of the Cyanate Inhibited State of Cytochrome c Oxidase. Sci. Rep. 2020, 10, 3863. [CrossRef] [PubMed]

12. Hitaishi, V.P.; Clément, R.; Quattrocchi, L.; Parent, P.; Duché, D.; Zuily, L.; Ilbert, M.; Lojou, E.; Mazurenko, I. Interplay between Orientation at Electrodes and Copper Activation of Thermus thermophilus Laccase for $\mathrm{O}_{2}$ Reduction. J. Am. Chem. Soc. 2020, 142, 1394-1405. [CrossRef] [PubMed]

13. Agbo, P.; Heath, J.R.; Gray, H.B. Modeling Dioxigen Reduction at Multicopper Oxidase Cathodes. J. Am. Chem. Soc. 2014, 136, 13882-13887. [CrossRef] [PubMed]

14. Mateljak, I.; Monza, E.; Lucas, M.F.; Guallar, V.; Aleksejeva, O.; Ludwig, R.; Leech, D.; Shleev, S.; Alcalde, M. Increasing redox potential, redox mediator activity, and stability in a fungal laccase by computer-guided mutagenesis and directed evolution. ACS Catal. 2019, 9, 4561-4572. [CrossRef]

15. Morozova, O.V.; Shumakovich, G.P.; Shleev, S.V.; Yaropolov, Y.I. Laccase-mediator systems and their applications: A review. Appl. Biochem. Microbiol. 2007, 43, 523-535. [CrossRef]

16. Yin, H.; Tnag, Z. Electron highways. Nat. Energy 2018, 3, 543-544. [CrossRef]

17. Tylkowski, B.; Trojanowska, A.; Marturano, V.; Nowak, M.; Marciniak, L.; Giamberini, M.; Ambrogi, V.; Cerruti, P. Power of light-Functional complexes based on azobenzene molecules. Coord. Chem. Rev. 2017, 351, 205-217. [CrossRef]

18. Naaman, R.; Paltiel, Y.; Waldeck, D.H. Chiral molecules and the electron spin. Nat. Rev. Chem. 2019, 3, 250-260. [CrossRef]

19. Kettner, M.; Göhler, B.; Zacharias, H.; Mishra, D.; Kiran, V.; Naaman, R.; Waldeck, D.H.; Sek, S.; Pawlowski, J.; Juhaniewicz, J. Spin Filtering in Electron Transport Through Chiral Oligopeptides. J. Phys. Chem. C 2015, 119, 14542-14547. [CrossRef]

20. Onami, Y.; Koya, R.; Kawasaki, T.; Aizawa, H.; Nakagame, R.; Miyagawa, Y.; Haraguchi, T.; Akitsu, T.; Tsukiyama, K.; Palafox, M.A. Investigation by DFT methods of the damage of human serum albumin including amino acid derivative schiff base Zn(II) complexes by IR-FEL irradiation. Int. J. Mol. Sci. 2019, 20, 2846. [CrossRef]

21. Zou, Y.; Yin, F.; Zhou, X.-J.; Chen, J.; Meng, Q.-J. A Cu ${ }^{\mathrm{II}}-\mathrm{Gd}^{\mathrm{III}}-\mathrm{Cu}^{\mathrm{II}}$ heterometallic coordination polymer constructed by gadolinium(III) ion and copper(II) Schiff-base building block: Structure and magnetic property. Inorg. Chem. Commun. 2014, 45, 25-29. [CrossRef]

22. Mitsumoto, Y.; Sunaga, N.; Akitsu, T. Polarized light induced molecular orientation in laccase for chiral azosalen $\mathrm{Mn}(\mathrm{II}), \mathrm{Co}(\mathrm{II}), \mathrm{Ni}(\mathrm{II}), \mathrm{Cu}(\mathrm{II}), \mathrm{Zn}(\mathrm{II})$ mediators toward application for biofuel cell. SciFed J. Chem. Res. 2017, 1, 1 .

23. Sheldrick, G.M. A short history of SHELX. Acta Crystallogr. Sect. A 2008, 64, 112-122. [CrossRef] [PubMed] 
24. Frisch, M.J.; Trucks, G.W.; Schlegel, H.B.; Scuseria, G.E.; Robb, M.A.; Cheeseman, J.R.; Scalmani, G.; Barone, V.; Mennucci, B.; Petersson, G.A.; et al. Gaussian 09, Revision D.01; Gaussian, Inc.: Wallingford, CT, USA, 2009.

25. GOLD has Proven Success in Virtual Screening, Lead Optimisation, and Identifying the Correct Binding Mode of Active Molecules. Available online: https://www.ccdc.cam.ac.uk/solutions/csd-discovery/Components/ Gold/ (accessed on 8 May 2020).

26. A Structural View of Biology. Available online: http://www.rcsb.org/ (accessed on 8 May 2020).

27. Takeshita, Y.; Takakura, K.; Akitsu, T. Multifunctional composites of chiral valine derivative schiff base $\mathrm{Cu}$ (II) complexes and $\mathrm{TiO}_{2}$. Int. J. Mol. Sci. 2015, 16, 3955-3969. [CrossRef] [PubMed]

28. Nakagame, R.; Tsaturyan, A.; Haraguchi, T.; Pimonova, Y.; Lastovina, T.; Akitsu, T.; Shcherbakov, I. Photochemical reaction of amino acid Schiff base derived $\mathrm{Cu}$ complexes with extended $\pi$-system and their titanium oxide composites. Inorg. Chim. Acta 2019, 486, 221-231. [CrossRef]

29. Aritake, Y.; Takanashi, T.; Yamazaki, A.; Akitsu, T. Polarized spectroscopy and hybrid materials of chiral Schiff base $\mathrm{Ni}(\mathrm{II}), \mathrm{Cu}(\mathrm{II}), \mathrm{Zn}(\mathrm{II})$ complexes with included or separated azo-groups. Polyhedron 2011, 30 , 886-894. [CrossRef]

30. Akitsu, T. Photofunctional supramolecular solution systems of chiral Schiff base nickel(II), copper(II), and zinc(II) complexes and photochromic azobenzenes. Polyhedron 2007, 26, 2527-2535. [CrossRef]

31. Sano, A.; Yagi, S.; Haraguchi, T.; Akitsu, T. Synthesis of Mn (II) and, Cu (II) complexes including azobenzene and its application to mediators of laccase for biofuel cells. J. Indian Chem. Soc. 2018, 95, 487-494.

32. Kunitake, F.; Kim, J.-Y.; Yagi, S.; Yamazaki, S.; Haraguchi, T.; Akitsu, T. Chiral recognition of azo-Schiff base ligands, their $\mathrm{Cu}$ (II) complexes and their docking to laccase as mediators. Symmetry 2019, 11, 666. [CrossRef]

33. Kurosawa, Y.; Tsuda, E.; Takase, M.; Yoshida, N.; Takeuchi, Y.; Mitsumoto, Y.; Akitsu, T. Spectroscopic and electrochemical studies on metalloprotein (laccase) and $\mathrm{Cu}(\mathrm{II})$ complex mediators as model systems for biofuel cell cathodes. In Threonine: Food Sources, Functions and Health Benefits; Nova Science Publishers Inc.: Hauppauge, NY, USA, 2015; Chapter 4; pp. 73-86.

34. Takeuchi, Y.; Akitsu, T. Anthraquinone derivative chiral schiff base Copper(II) complexes for enzyme type bio-fuel cell mediators. J. Electr. Eng. 2016, 4, 189-195. [CrossRef]

35. Takeuchi, Y.; Sunaga, N.; Akitsu, T. Anthraquinone and L-amino acid derivatives schiff base Cu(II) complexes as a mediator between cathode of biofuel cell and oxygen-reducing laccase. Trend Green Chem. 2017, 3, 1-8. [CrossRef]

36. Cheng, C.-Y.; Liao, C.-I.; Lin, S.-F. Borate-fructose complex: A novel mediator for laccase and its new function for fructose determination. FEBS Lett. 2015, 589, 3107-3112. [CrossRef]

37. Kominato, C.; Akitsu, T. Photoinduced molecular orientation of catalytic-like chiral azo-Schiff base complexes in PMMA or laccase matrices. Lett. Appl. NanoBioSci 2015, 2, 264-270.

38. Kiran, V.; Cohen, S.R.; Naaman, R. Structure dependent spin selectivity in electron transport through oligopeptides. J. Chem. Phys. 2016, 146, 092302. [CrossRef]

39. Mondal, P.C.; Fontanesi, C.; Waldeck, D.H.; Naaman, R. Spin-dependent transport through chiral molecules studied by spin-dependent electrochemistry. Acc. Chem. Res. 2016, 49, 2560-2568. [CrossRef]

40. Naaman, R.; Waldeck, D.H. Chiral-Induced Spin Selectivity Effect. J. Phys. Chem. Lett. 2012, 3, $2178-2187$. [CrossRef]

41. Kumar, K.S.; Kantor-Uriel, N.; Mathew, S.P.; Guliamov, R.; Naaman, R. A device for measuring spin selectivity in electron transfer. Phys. Chem. Chem. Phys. 2013, 15, 18357-18362. [CrossRef]

42. Michaeli, K.; Naaman, R. Origin of spin dependent tunneling through chiral molecules. arXiv 2016, arXiv:1512.03435v2. [CrossRef]

43. Yang, X.; van der Wal, C.H.; van Wees, B.J. Spin-dependent electron transmission model for chiral molecules in mesoscopic devices. Phys. Rev. B 2019, 99, 024418. [CrossRef]

44. Göhler, B.; Hamelbeck, V.; Markus, T.Z.; Kettner, M.; Hanne, G.F.; Vager, Z.; Naaman, R.; Zacharias, H. Spin selectivity in electron transmission through self-assembled monolayers of double-stranded DNA. Science 2011, 331, 894-897. [CrossRef]

45. Kumar, A.; Capua, E.; Kesharwani, M.K.; Martin, J.M.L.; Sitbon, E.; Waldeck, D.H.; Naaman, R. Chirality-induced spin polarization places symmetry constrains on bimolecular interaction. Proc. Natl. Acad. Sci. USA 2017, 114, 2474-2478. [CrossRef] [PubMed] 
46. Shimada, S.; Shinzawa-Itoh, K.; Baba, J.; Aoe, S.; Shimada, A.; Yamashita, E.; Kang, J.; Tateno, M.; Yoshikawa, S.; Tsukihara, T. Complex structure of cytochrome c-cytochrome c oxidase reveals a novel protein-protein interaction mode. EMBO J. 2017, 36, 291-300. [CrossRef] [PubMed]

47. Eckshtain-Levi, M.; Capua, E.; Refaely-Abramson, S.; Sarkar, S.; Gavrilov, Y.; Mathew, S.P.; Paltiel, Y.; Levy, Y.; Kronik, L.; Naaman, R. Cold denaturation induces inversion of dipole and spin transfer in chiral peptide monolayers. Nat. Commun. 2016, 7, 10744. [CrossRef] [PubMed]

48. Milton, R.D.; Minteer, S.D. Direct enzymatic bioelectrocatalysis: Differentiating between myth and reality. J. R. Soc. Interface 2017, 14, 20170253. [CrossRef]

(C) 2020 by the authors. Licensee MDPI, Basel, Switzerland. This article is an open access article distributed under the terms and conditions of the Creative Commons Attribution (CC BY) license (http://creativecommons.org/licenses/by/4.0/). 